\title{
Sea level budget over 2005-2013: missing contributions and data errors
}

\author{
H. B. Dieng ${ }^{1}$, A. Cazenave ${ }^{1,2}$, K. von Schuckmann ${ }^{3}$, M. Ablain ${ }^{4}$, and B. Meyssignac ${ }^{1}$ \\ ${ }^{1}$ Laboratoire d'Etudes en Géophysique et Océanographie Spatiales - Centre National d'Etudes Spatiales \\ (LEGOS-CNES), Toulouse, France \\ ${ }^{2}$ International Space Science Institute (ISSI), Bern, Switzerland \\ ${ }^{3}$ Mediterranean Institute of Oceanography (MIO), Université de Toulon, Toulon, France \\ ${ }^{4}$ Collecte Localisation Satellites (CLS), Ramonville, France
}

Correspondence to: A. Cazenave (anny.cazenave@legos.obs-mip.fr)

Received: 7 April 2015 - Published in Ocean Sci. Discuss.: 13 May 2015

Revised: 27 July 2015 - Accepted: 30 July 2015 - Published: 6 October 2015

\begin{abstract}
Based on the sea level budget closure approach, this study investigates the residuals between observed global mean sea level (GMSL) and the sum of components (steric sea level and ocean mass) for the period January 2005 to December 2013. The objective is to identify the impact of errors in one or several components of the sea level budget on the residual time series. This is a key issue if we want to constrain missing contributions such as the contribution to sea level rise from the deep ocean (depths not covered by observations). For that purpose, we use several data sets as processed by different groups: six altimetry products for the GMSL, four Argo products plus the ORAS4 ocean reanalysis for the steric sea level and three GRACE-based ocean mass products. We find that over the study time span, the observed differences in trend of the residuals of the sea level budget equation can be as large as $\sim 0.55 \mathrm{~mm} \mathrm{yr}^{-1}$ (i.e., $\sim 17 \%$ of the observed GMSL rate of rise). These trend differences essentially result from differences in trends of the GMSL time series. Using the ORAS4 reanalysis (providing complete geographical coverage of the steric sea level component), we also show that lack of Argo data in the Indonesian region leads to an overestimate of the absolute value of the residual trend by about $0.25 \mathrm{~mm} \mathrm{yr}^{-1}$. Accounting for this regional contribution leads to closure of the sea level budget, at least for some GMSL products. At short timescales (from subseasonal to interannual), residual anomalies are significantly correlated with ocean mass and steric sea level anomalies (depending on the time span), suggesting that the residual anomalies are related to errors in both GRACE-based ocean
\end{abstract}

mass and Argo-based steric data. Efforts are needed to reduce these various sources of errors before using the sea level budget approach to estimate missing contributions such as the deep ocean heat content.

\section{Introduction}

For the 1993-2010 time span of the high-precision satellite altimetry era, the Fifth Assessment Report (AR5) of the Intergovernmental Panel on Climate Change (IPCC) reported that the rate of global mean sea level (GMSL) rise could be explained by the combined effects of land ice melt $(42 \%)$, ocean thermal expansion (34\%) and anthropogenic land water storage decrease (12\%) (Church et al., 2013). Over this period, GMSL rise observed by altimeter satellites amounted to $3.2 \pm 0.4 \mathrm{~mm} \mathrm{yr}^{-1}$, a value only slightly higher than the sum of the contributions (amounting to $2.8 \pm 0.5 \mathrm{~mm} \mathrm{yr}^{-1}$ ). Although of the same order of magnitude as associated uncertainties, the $0.4 \mathrm{~mm} \mathrm{yr}^{-1}$ difference may also reflect missing contributions, e.g., the deep ocean contribution below $700 \mathrm{~m}$ depth where the coverage of ocean temperature data before the Argo era was poor. Estimating the deep ocean warming is an important issue in the context of the current hiatus reported since the early 2000s in global mean air and sea surface temperature evolution (e.g., Held, 2013; Trenberth and Fasullo, 2013; Smith, 2013). Different explanations have been proposed to explain the hiatus, ranging from reduced radiative forcing due to prolonged solar minimum, 
increased aerosol emissions and small numerous volcanic eruptions, changes in stratospheric water vapor, enhanced heat uptake by the deep ocean, either in the Pacific or Atlantic regions (e.g., Trenberth and Fasullo, 2010, 2013; Hansen et al., 2011; Solomon et al., 2010; Guemas et al., 2013; Kosaka and Xie, 2013; Balmaseda et al., 2013a; Watanabe et al., 2013; England et al., 2014; Chen and Tung, 2014), to redistribution of heat in the Indo-Pacific region (Nieves et al., 2015). The deep ocean heat uptake has so far been the favored explanation of the hiatus considering that greenhouse gases continue to accumulate in the atmosphere at an increasing rate (Peters et al., 2012) and the Earth's energy imbalance at the top of the atmosphere is still in the range $0.5-1 \mathrm{Wm}^{-2}$ (e.g., Hansen et al., 2011; Loeb et al., 2012; Trenberth et al., 2014). A recent study by Karl et al. (2015) based on reprocessing of ocean and land surface temperature data claims that there is no evidence of a hiatus during the last decade. While the hiatus is still a matter of debate, attempts to estimate whether and how much the deep ocean is warming remains an important issue. Accurate observations of sea level rise and its components (ocean thermal expansion and ocean mass change) can, in principle, help in constraining the deep ocean contribution, hence its amount of warming (e.g., von Schuckmann et al., 2014). In particular, satellite altimetry-based GMSL rise corrected for ocean mass change (for example, using GRACE space gravimetry data over the oceans) provides an estimate of the total (full depth-integrated) ocean thermal expansion (or equivalently ocean heat content). Since the year 2005, comparison with observed Argo-based ocean thermal expansion (down to $\sim 2000 \mathrm{~m}$ depth) may help to quantify any deep ocean contribution (below $2000 \mathrm{~m}$ ). In effect, the sea level budget equation is described as follows:

$$
\begin{aligned}
\text { GMSL } & =\text { Ocean Mass }+ \text { Steric sea level }(0-2000 \mathrm{~m}) \\
& + \text { Steric sea level }(>2000 \mathrm{~m})+\text { data errors }
\end{aligned}
$$

The residual term defined as the difference between observed GMSL and observed estimates of ocean mass and steric sea level down to $2000 \mathrm{~m}$ depth (see Eq. 2 below) includes the deep ocean contribution (called "Steric sea level > 2000 m") and data errors:

$$
\begin{aligned}
\text { Residual } & =\text { GMSL }- \text { Ocean mass }- \text { Steric sea level }(0-2000 \mathrm{~m}) \\
& =\text { Steric sea level }(>2000 \mathrm{~m})+\text { data errors. }
\end{aligned}
$$

Attempts to estimate the deep ocean contribution from the sea level budget approach were performed in two recent studies (Llovel et al., 2014; Dieng et al., 2015). Dieng et al. (2015) considered two periods (2005-2012 and 20032012) that correspond to the availability of new observing systems for estimating thermal expansion and ocean mass (nearly full ocean temperature and salinity coverage down to $2000 \mathrm{~m}$ from Argo floats and direct ocean mass measurements from GRACE space gravimetry, respectively). In Dieng et al. (2015), time series of satellite altimetry-based sea level (five different data sets), thermal expansion (eight different products; integration down to $1500 \mathrm{~m}$ ) and ocean mass (three products) components were analyzed in order to estimate the residual term of Eq. (2). Llovel et al. (2014) performed a similar study over the 2005-2013 time span but with fewer data sets. Another attempt concerning this issue is by von Schuckmann et al. (2014). These studies came to the same conclusion; i.e., the residual term in Eq. (2) is contaminated by overly large data errors to provide any robust deep ocean contribution estimate. Here we build upon these previous studies, in particular that from Dieng et al. (2015). We focus on the 2005-2013 time span corresponding to maximized Argo coverage and compute the steric sea level component integrating the data down to $2000 \mathrm{~m}$. We also include in our analysis the new sea level product from the European Space Agency (ESA) Climate Change Initiative (CCI) project (www.esa-sealevel-cci.org), available up to December 2013. The main objective of the present study is to investigate whether the residual time series of the sea level budget (Eq. 2) may be attributed to errors associated with the components (GMSL, ocean mass, steric sea level) or not. This is an important issue to be addressed before trying to estimate any missing contribution.

\section{Data and method}

\subsection{Sea level data}

We used six different products from six processing groups for the altimetry-based sea level data:

1. Validation and Interpretation of Satellite Oceanographic (AVISO; http://www.aviso.altimetry.fr/en/data/products/oceanindicators-products/actualitesindicateurs-desoceansniveau-moyen-des-mersindexhtml.html);

2. University of Colorado (CU Release 5; http://sealevel. colorado.edu/);

3. National Oceanographic and Atmospheric Administration (NOAA; http://www.star.nesdis.noaa.gov/sod/lsa/ SeaLevelRise/LSA_SLR_timeseries_global.php);

4. Goddard Space Flight Center (GSFC version 2; http://podaac-ftp.jpl.nasa.gov/dataset/MERGED_TP_ J1_OSTM_OST_GMSL_ASCII_V2);

5. Commonwealth Scientific and Industrial Research Organization (CSIRO; www.cmar.csiro.au/sealevel/sl_ data_cmar.html); and

6. the CCI sea level data (http://www.esa-sealevel-cci.org/ products).

The first five sea level data sets are based on Topex/Poseidon, Jason- 1 and Jason- 2 data averaged over the $66^{\circ} \mathrm{S}-66^{\circ} \mathrm{N}$ domain, except for the CSIRO data averaged over $65^{\circ} \mathrm{S}$ to 
Table 1. Trends estimated over January 2005-December 2013 for the GMSL, global ocean mass, Argo-based steric sea level, and residuals. Errors associated with "mean global ocean mass" and "mean Argo-based steric sea level" are estimated from the dispersion around the mean.

\begin{tabular}{llr}
\hline $\begin{array}{l}\text { Global mean } \\
\text { sea level } \\
\text { (GMSL) } \\
\text { product }\end{array}$ & GMSL trends $\left(\mathrm{mm} \mathrm{yr}^{-1}\right)$ & $\begin{array}{r}\text { Residual trends }\left(\mathrm{mm} \mathrm{yr}^{-1}\right) \\
\text { (residual computed with mean } \\
\text { global ocean mass and mean } \\
\text { Argo-based steric sea level) }\end{array}$ \\
\hline AVISO & 3.17 & 0.3 \\
CU & 2.83 & -0.03 \\
NOAA & 3.26 & 0.42 \\
GSFC & 2.80 & -0.07 \\
CSIRO & 3.35 & 0.49 \\
CCI & 3.11 & 0.26 \\
\hline Global ocean & Global ocean mass trends & CCI residual trends \\
mass & $\left(\right.$ mm yr $\left.{ }^{-1}\right)$ & 0.28 \\
\hline CSR & 2.01 & 0.18 \\
GFZ & 2.11 & 0.29 \\
JPL & 2.00 & \\
Mean & $2.04 \pm 0.08$ & CCI residual trends \\
\hline Argo-based steric & Argo-based steric sea & $\left(\mathrm{mm} \mathrm{yr}^{-1}\right)$ \\
sea level & level trends (mm yr $\left.{ }^{-1}\right)$ & 0.33 \\
\hline KVS & $0.74 \pm 0.13$ & 0.31 \\
IPRC & 0.76 & 0.14 \\
JAMSTEC & $0.94 \pm 0.16$ & 0.24 \\
SCRIPPS & 0.83 & -0.06 \\
Mean & $0.82 \pm 0.08$ & \\
ORAS4 (0-5350 m) & 1.14 & \\
\hline
\end{tabular}

$65^{\circ} \mathrm{N}$. For each product, a set of instrumental and geophysical corrections is applied (details are given on the websites of each data set). In addition, the effect of glacial isostatic adjustment (GIA, i.e., a small correction of $-0.3 \mathrm{~mm} \mathrm{yr}^{-1}$; Peltier, 2004) is accounted for in each sea level time series except for the NOAA data set. Thus we corrected the latter for the GIA effect, using the $-0.3 \mathrm{~mm} \mathrm{yr}^{-1}$ value (i.e., resulting in an addition of $0.3 \mathrm{~mm} \mathrm{yr}^{-1}$ to the GMSL time series). The sea level time series used in this study cover the period January 1993-December 2013. The five sea level time series (AVISO, CU, GSFC, NOAA and CSIRO) are obtained either by directly averaging the along-track sea surface height data (e.g., CU) or by firstly gridding the unevenly distributed along-track data and then performing grid averaging (e.g., AVISO and NOAA). In all cases, an area weighting is applied. In addition to the geographical averaging method, other differences exist between the GMSL data sets because of the applied geophysical and instrumental corrections and the number of satellites considered (discussion on these differences can be found in Masters et al., 2012, and Henry et al., 2014).

In the context of the ESA CCI Sea Level project, a new, improved product has been computed. It combines data from Topex/Poseidon, Jason-1 and Jason-2 with the ERS-1 and ERS-2 and Envisat missions, and is based on a new processing system with dedicated algorithms and adapted data processing strategies (Ablain et al., 2015). The main improvements include reduction of errors in the orbit solutions and wet/dry atmospheric corrections, reduction of instrumental drifts and biases, improved inter-calibration between satellite altimetry missions and optimized combination of the different sea level data sets. The CCI sea level products have been validated using different approaches, including a comparison with tide gauge records as well as with ocean re-analysis and climate model outputs (see Ablain et al., 2015, for more details). The CCI sea level data set is freely available over January 1993-December 2013.

Figure 1a shows the GMSL time series from January 2005 to December 2013 for the six products presented above. Trend values estimated over this time span are given in Table 1 . We first note important trend differences between all GMSL time series, up to $0.55 \mathrm{~mm} \mathrm{yr}^{-1}$ between GFSC and CSIRO data. The lowest trends (around $2.8 \mathrm{~mm} \mathrm{yr}^{-1}$ ) are obtained for the CU and GSFC data sets. Higher trends (from 3.11 to $3.35 \mathrm{~mm} \mathrm{yr}^{-1}$ ) are obtained for CCI, AVISO, NOAA and CSIRO GMSL time series. At shorter timescales (from sub-seasonal to multi-annual), significant discrepancies of several $\mathrm{mm}$ are observed between the different GMSLs, especially between 2005 and 2008, and between mid-2010 and mid-2011. The latter period coincides with a strong La Niña event.

\subsection{Ocean mass data}

We use three different data sets for estimating the ocean mass component: the GRACE Release 05 products from the Center for Space Research of the University of Texas (CSR RL05), the Deutsches GeoForschungsZentrum (GFZ RL05) and the Jet Propulsion Laboratory (JPL RL05). The GRACE Release 05 ocean mass data have been specifically processed by D. Chambers to study the ocean mass temporal evolution (data available at http://grace.jpl.nasa.gov). In effect, gridded Release 05 data cannot be used to compute ocean mass changes because the area-weighted global mean is set to zero (as warned on the http://grace.jpl.nasa. gov/data/get-data/monthly-mass-grids-ocean website). The Chambers RL05 GRACE ocean data are publicly available from https://dl.dropboxusercontent.com/u/31563267/ocean mass_orig.txt. They are provided as global mean (averaged over the $90^{\circ} \mathrm{S}-90^{\circ} \mathrm{N}$ domain) time series with associated uncertainties. The data processing is described in Johnson and Chambers (2013) (see also Chambers and Schroeter, 2011, and Chambers and Bonin, 2012). The GIA component has been subtracted from each GRACE ocean mass time series using the GIA correction computed as described in Chambers et al. (2010). Figure 1b shows the global ocean mass (called GOM hereafter) time series and associated uncertainties over 2005-2013 for the CSR, GFZ and JPL products (see also Table 1 for trend values and associated uncertainties; note that mean value uncertainties quoted in Table 1 are estimated from the dispersion between available products. These represent lower bounds of errors). All three GOM products 
(a)

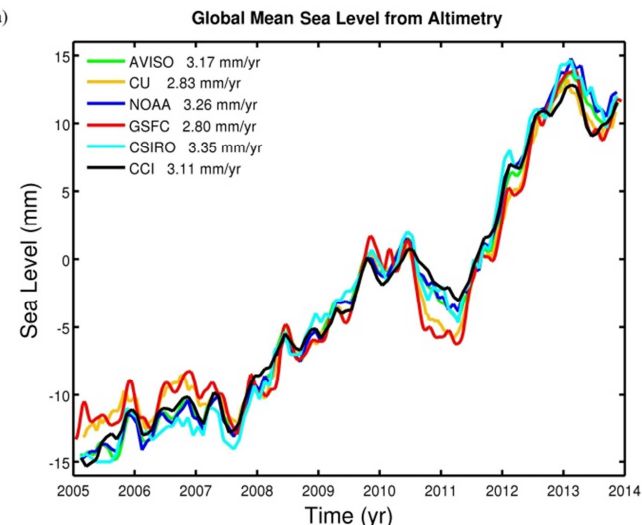

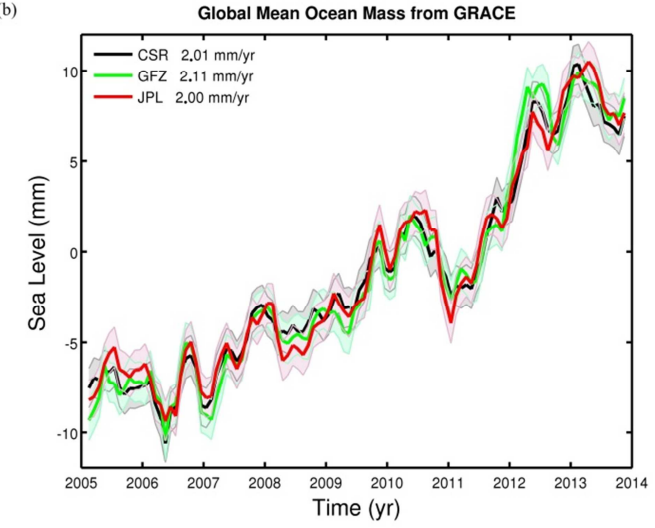

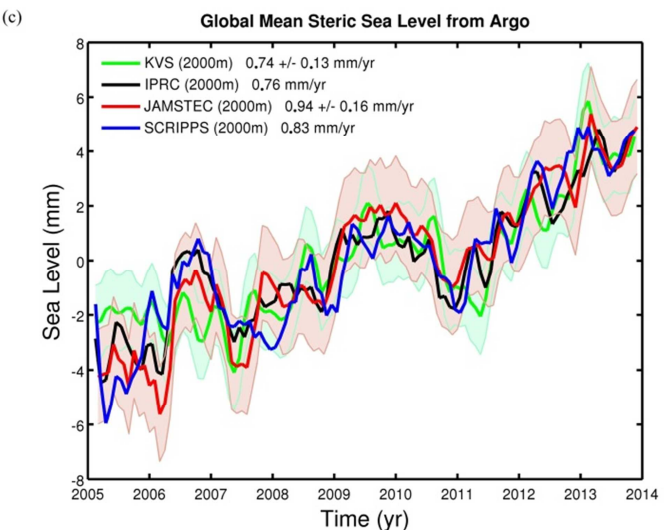

Figure 1. (a) Global mean sea level (GMSL) time series (January 2005-December 2013) from the five satellite altimetry processing groups (AVISO, CU, NOAA, GSFC and CSIRO) and CCI. (b) Global ocean mass (GOM) time series and associated uncertainty (shaded area) (January 2005-December 2013) from GRACE, based on the data from CSR (black curve), GFZ (green curve) and JPL (red curve). (c) Argobased monthly global mean steric sea level time series (January 2005-December 2013) (integration down to $2000 \mathrm{~m}$ ) from four processing groups (KVS, IPRC, JAMSTEC and SCRIPPS). Shaded areas represent uncertainties of the JAMSTEC and KVS steric sea level data.

are quite close to each other, in terms of both trend and shortterm fluctuations.

\subsection{Steric data}

We used four Argo temperature and salinity data sets.

Three gridded data sets are provided by the following groups:

- the International Pacific Research Center (IPRC; http://apdrc.soest.hawaii.edu/projects/Argo/data/ gridded/On_standard_levels/index-1.html);

- the Japan Agency for Marine-Earth Science and Technology (JAMSTEC; ftp://ftp2.jamstec.go.jp/pub/argo/ MOAA_GPV/Glb_PRS/OI/); and

- the SCRIPPS Institution of Oceanography (SCRIPPS; http://sio-argo.ucsd.edu/RG_Climatology.html).

These data sets are available at monthly intervals on a global $1^{\circ} \times 1^{\circ}$ grid down to $2000 \mathrm{~m}$, over the period January 2005 to
December 2013, January 2001 to August 2014, and January 2004 to December 2013, respectively.

Argo data sets do not cover the whole ocean before 2005 (von Schuckmann et al., 2014; Roemmich et al., 2015). The study by Chen and Tung (2014) provides a depth coverage map of in situ temperature and salinity measurements, and we note that as of 2005 , there are data up to at least $1500 \mathrm{~m}$ (e.g., almost full coverage down to $1200 \mathrm{~m}$ and $50 \%$ coverage between 1200 and $1500 \mathrm{~m}$ ). Thus we computed the steric sea level time series (and associated uncertainty; but note that only JAMSTEC provides errors), over January 2005-December 2013, integrating the data over the 0 $2000 \mathrm{~m}$ depth range. The global mean steric sea level time series from IPRC, JAMSTEC and SCRIPPS are estimated over the $62.5^{\circ} \mathrm{S}-64.5^{\circ} \mathrm{N}, 60.5^{\circ} \mathrm{S}-66^{\circ} \mathrm{N}$ and $61.5^{\circ} \mathrm{S}-64.5^{\circ} \mathrm{N}$ domains, respectively.

We also used an updated version of the steric data set processed by von Schuckmann and Le Traon (2011). This data set provides steric sea level and associated uncertainty based 


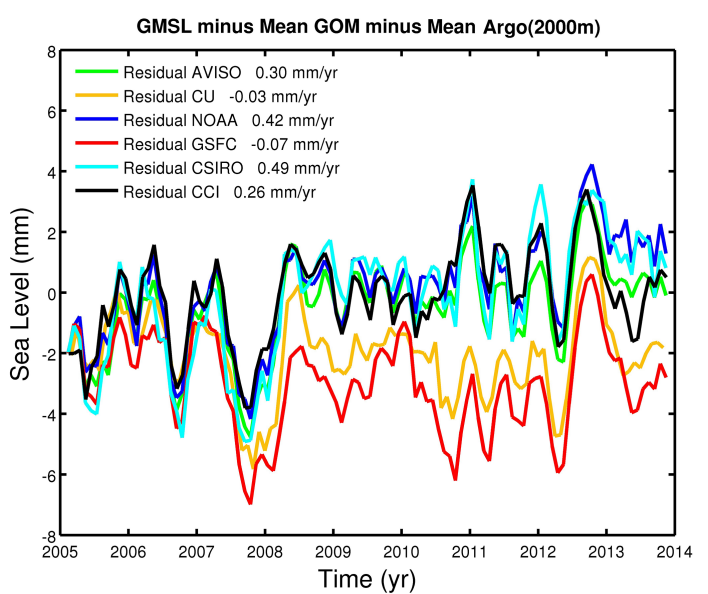

Figure 2. Residual curves (January 2005-December 2013) computed for each of the six GMSL products (AVISO, CU, NOAA, GSFC, CSIRO and CCI). Mean global ocean mass (GOM) and mean Argo-based steric sea level are used. (For example: "Residual AVISO" = "GMSL from AVISO minus Mean GOM minus Mean Argo".)

on quality-controlled Argo-based temperature and salinity data from IFREMER (http://wwz.ifremer.fr/lpo_eng/content/ view/full/83074), with integration down to $2000 \mathrm{~m}$ depth and averaged on a $5^{\circ} \times 10^{\circ}$ grid. The method to derive the gridded products is described in detail in von Schuckmann and Le Traon (2011). In the following, we call this data set "KVS". The KVS data set covers the $60^{\circ} \mathrm{S}-60^{\circ} \mathrm{N}$ domain. Area weighting is applied to all data sets when averaging.

Figure 1c presents the four steric sea level time series and associated uncertainties (except for IPRC and SCRIPPS, for which errors are not provided) over 2005-2013. Trend values over the study time span can be found in Table 1. Figure 1c shows significant discrepancies of several $\mathrm{mm}$ from one time series to another at sub-seasonal to interannual timescales, in particular in the early part of the record (e.g., in 2005) and late 2007 to early 2008. Between 2005 and early 2008, the KVS time series is rather flat, unlike the other steric time series. In terms of trends, we note differences of up to $0.2 \mathrm{~mm} \mathrm{yr}^{-1}$, the KVS data giving a lower steric trend than the other three (this is actually due to the rather flat start of the KVS curve in 2005).

Finally, we include the ORAS4 reanalysis from Balmaseda et al. (2013b) (https://icdc.zmaw.de/easy_init_ocean. html?\&L=1\#c2231). This reanalysis is based on the Nucleus for European Modelling of the Ocean (NEMO) circulation model (version 3.0) with data assimilation. Assimilated data include temperature and salinity profiles over 1958-2009 from the v2a version of the EN3 database constructed by the Met Office Hadley Centre (Good et al., 2013), alongtrack altimetry-based sea level anomalies and global sea level trend from AVISO, sea surface temperature and sea ice from the ERA-40 archive (prior to November 1981), from NCEP
(National Centers for Environmental Prediction) OI version 2 (1981 until December 2009) and from OSTIA (Operational Sea Surface Temperature and Sea Ice Analysis; January 2010 onwards). The ORAS4 temperature and salinity data are available at monthly intervals over 42 depth levels ranging from the ocean surface down to $5350 \mathrm{~m}$ depth, on a global $1^{\circ} \times 1^{\circ}$ grid from January 1958 to December 2014 (see Balmaseda, 2013b, for more details). To estimate the ORAS4 global mean steric sea level, the data are averaged over the $66^{\circ} \mathrm{S}-66^{\circ} \mathrm{N}$ domain.

Steric sea level trends and associated uncertainties are gathered in Table 1.

\section{Residual time series (GMSL minus ocean mass minus steric sea level)}

In the following, we present the residual time series (Eq. 2, called "residuals" hereinafter) over January 2005-December 2013. The main objective is to check whether the residual anomalies are correlated - or not - with one or several components of the sea level budget (GMSL, ocean mass, steric sea level; see Eq. 1). In a first step (Sect. 4), we look at residual trends, focusing on the trend differences between the residual time series obtained with different components (and different products for each component). These differences only inform on the residual trend obtained from a given combination of products, relative to other residual trends. They say nothing about the absolute residual trend values. In Sect. 8, we also estimate uncertainty of the absolute trend of the residuals.

In a second step (Sect. 5), we try to explain the shortterm (from sub-seasonal to interannual) anomalies in the detrended residual time series and investigate whether these are real signals or errors in one or several components of the sea level budget equation. For that purpose, we correlate the detrended residual with each detrended component, successively. A significant correlation of the residuals with one component of the budget equation (GMSL, ocean mass, steric sea level) may indicate that this particular component is in error. In effect, if one (or more than one) component is error free, one may expect no correlation between the shortterm anomalies of the residual time series and that particular component, since in that case this component should be compensated for by the sum of the other two components of the budget equation (Eq. 1).

\section{Residuals with trends}

Figure 2 shows residual time series computed for each GMSL estimate (i.e., AVISO, CU, NOAA, GSFC, CSIRO and $\mathrm{CCI}$ ), using mean values of the three GOM and four Argo-based steric sea level products. For the comparison, all curves start at the same (arbitrary) value in January 2005. Table 1 gathers the trend values over January 2005-December 2013 of the residual time series for the different data com- 


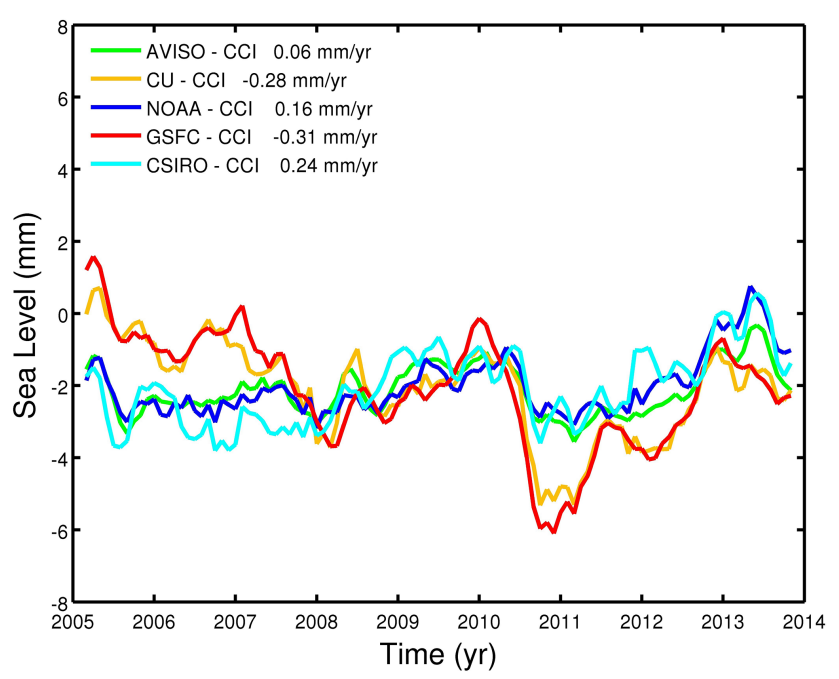

Figure 3. Time series of GMSL differences with respect to the CCI GMSL (January 2005-December 2013).

binations. Figure 2 indicates that over the January 2005February 2007 time span, the residuals are in fairly good agreement. In late 2007 (a period coinciding with the 20072008 La Niña), all residuals are strongly negative. By mid2008, we observe a step-like increase in the residuals associated with some GMSL time series (AVISO, NOAA, CSIRO and $\mathrm{CCI}$ ), while a decrease is noticed for the CU and GSFC residuals until mid-to-late 2011. The residual trends seem to fall into two groups (see Table 1): (1) AVISO, NOAA, CSIRO and CCI, and (2) CU and GSFC, with large trend differences, $>0.5 \mathrm{~mm} \mathrm{yr}^{-1}$, between them. The positive residual trends in Table 1 correspond to group 1, whereas residual trends of group 2 are negative.

Because the same "mean" ocean mass and "mean" steric sea level data are used when computing the residuals shown in Fig. 2, differences in residual trends necessarily result from trend differences in the GMSL time series. To investigate this further, we show in Fig. 3 difference time series between GMSL products, using the CCI GMSL as a reference.

The two groups of GMSL products mentioned above appear much more clearly in Fig. 3. We note that the AVISO, NOAA and CSIRO curves (corresponding to group 1) follow a different trajectory compared to the CU and GSFC curves (group 2), except during 2008-2010. This is particularly clear during 2005-2008 and to a lesser extent beyond 2010. The sources of these differences have been investigated in two recent papers by Masters et al. (2012) and Henry et al. (2014). These studies showed that the choice of the geophysical corrections applied to the data and the averaging method to calculate the GMSL from along-track data are the two main causes of differences between the GMSL time series. For example, AVISO and CU apply different averaging methods that significantly impact the GMSL products (Henry et al., 2014). Moreover, from 2005 to mid-2008, a time span corresponding to the use of Jason- 1 satellite data, these groups use different orbit solutions and different corrections for ocean tides and sea surface bias, while beyond mid-2008, they use exactly the same orbit solution and same sea surface bias correction (see the respective websites for more details). Thus, differences between AVISO and CU GMSL time series are to be expected over 2005 to mid-2008. This is indeed what Fig. 3 shows over this time span. To check the CU and GSFC residual drop somewhat further, we computed the residuals trends between January 2005 and June 2008 for all GMSL time series. We find highly negative related residual trends for CU and GFSC (of -0.67 and $-0.91 \mathrm{~mm} \mathrm{yr}^{-1}$, respectively), while for all other GMSL time series the residual trends are in the range -0.05 to $0.08 \mathrm{~mm} \mathrm{yr}^{-1}$. Other differences noticed in Fig. 3 beyond 2010 are less clear but may be related to the averaging method with a stronger impact during the $2011 \mathrm{La}$ Niña. More investigation and collaborative work between the different processing groups are needed to fully understand and reduce the reported differences in the GMSL time series.

In a next step, we examine the contribution of the ocean mass and steric components to the residual trend for each GMSL product. Figure $4 \mathrm{a}$ and $\mathrm{b}$ shows residual curves for the CCI GMSL computed with each ocean product and each steric sea level product. Results show that the different ocean mass products show almost similar residual trends (up to $\sim 0.1 \mathrm{~mm} \mathrm{yr}^{-1}$ trend differences are noted; see Fig. 4a). For the Argo products, their effect on the trend differences is $<0.2 \mathrm{~mm} \mathrm{yr}^{-1}$ (see Fig. 4b). We do not show similar figures for other GMSL products because the differences in the residual trends computed between all Argo products (and all ocean mass products as well) are similar to those computed with the CCI GMSL.

From this section, we conclude that trend differences observed in the residual time series (Fig. 2) are dominated by differences in the altimetry-based GMSL products.

\section{Detrended residuals}

Figure 2 shows that the residual time series also display important high-frequency (sub-seasonal to interannual) anomalies of up to $4 \mathrm{~mm}$ amplitude. These anomalies are highly correlated for all GMSL products, in particular for AVISO, NOAA, CSIRO and CCI data sets. In the following, we analyze the detrended residual time series. Only three GMSL data sets are considered: the AVISO, CU and CCI GMSL data (AVISO and CU being representative of group 1 and group 2, respectively). In order to understand whether a given variable (GMSL, ocean mass or steric sea level) is responsible for all - or part - of the observed short-term (from sub-seasonal to interannual) residuals, we correlate this variable (trend removed) with its associated (detrended) residual. What we would expect, if all data sets were error free, is to see no correlation between the detrended variable and its 


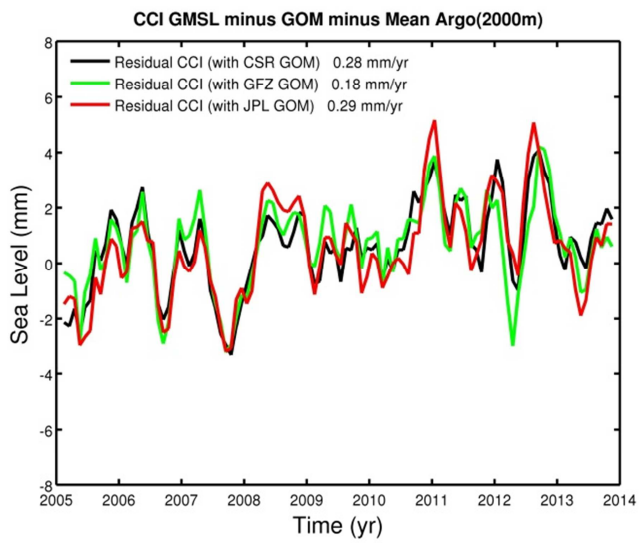

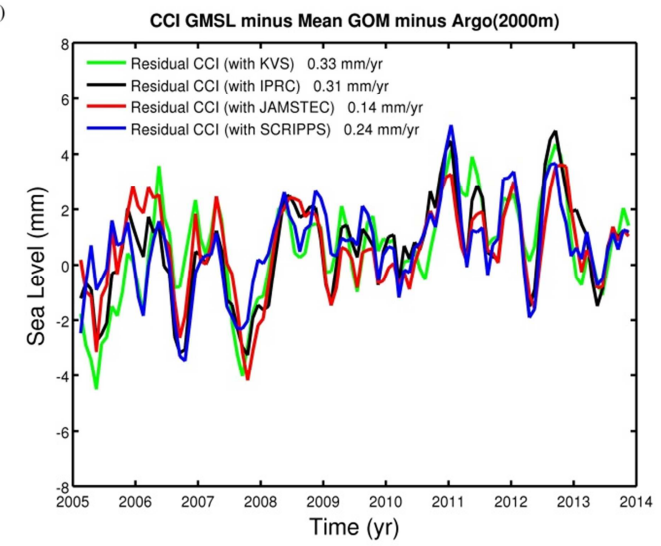

Figure 4. Residual sea level time series (January 2005-December 2013) computed with the CCI GMSL. (a) Mean of the four Argo products and each GOM product; (b) mean of the three global ocean mass (GOM) data sets and each Argo product.

Table 2. Correlations estimated between detrended residual time series and the associated detrended component. Estimated rms of the corresponding detrended residual time series.

\begin{tabular}{|c|c|c|}
\hline $\begin{array}{l}\text { Global mean } \\
\text { sea level } \\
\text { (GMSL) } \\
\text { product }\end{array}$ & $\begin{array}{r}\text { The rms of the residual computed } \\
\text { with mean global ocean mass } \\
\text { and mean Argo-based steric } \\
\text { sea level (mm) }\end{array}$ & $\begin{array}{r}\text { Correlation } \\
\text { (detrended GMSL } \\
\text { and associated } \\
\text { detrended residual) }\end{array}$ \\
\hline $\mathrm{CCI}$ & 1.38 & 0.02 \\
\hline AVISO & 1.32 & 0.26 \\
\hline $\mathrm{CU}$ & 1.36 & 0.55 \\
\hline $\begin{array}{l}\text { GRACE-based } \\
\text { global ocean } \\
\text { mass product }\end{array}$ & $\begin{array}{r}\text { The rms of the CCI residual } \\
\text { computed with mean } \\
\text { Argo-based steric sea } \\
\text { level }(\mathrm{mm})\end{array}$ & $\begin{array}{r}\text { Correlation } \\
\text { (detrended global ocean } \\
\text { mass and associated } \\
\text { detrended residual) }\end{array}$ \\
\hline CSR & 1.37 & 0.46 \\
\hline GFZ & 1.46 & 0.55 \\
\hline JPL & 1.56 & 0.57 \\
\hline $\begin{array}{l}\text { Argo-based } \\
\text { steric sea } \\
\text { level } \\
(0-2000 \mathrm{~m})\end{array}$ & $\begin{array}{r}\text { The rms of the CCI residual } \\
\text { computed with mean } \\
\text { global ocean mass } \\
(\mathrm{mm})\end{array}$ & $\begin{array}{r}\text { Correlation } \\
\text { (detrended steric sea } \\
\text { level and associated } \\
\text { detrended residual) }\end{array}$ \\
\hline KVS & 1.59 & 0.53 \\
\hline IPRC & 1.56 & 0.51 \\
\hline JAMSTEC & 1.56 & 0.51 \\
\hline SCRIPPS & 1.45 & 0.50 \\
\hline
\end{tabular}

associated (detrended) residual. Therefore, a low correlation may be interpreted as a "good result", i.e., little contamination by errors of the associated variable. Such an interpretation may not be unique however. Limitations of this approach are discussed in Sect. 6.

\subsection{GMSL short-term (from sub-seasonal to interannual) errors}

To analyze the impact of the short-term GMSL errors on the residuals, we simply superimpose the detrended GMSL with its associated residual (also detrended). Figure 5a-c shows, for AVISO, CU and CCI data, the detrended residual curves and associated detrended GMSL. In Table 2 are given the correlation between the detrended residual curve and its associated detrended GMSL as well as the root-mean squares (rms) of the residual time series. On sub-seasonal to interannual timescales, most of the observed GMSL anomalies have been reduced after subtracting the ocean mass and steric sea level components from the GMSL data. Nevertheless, some anomalies still remain (see Fig. 5a-c). This is particularly striking for the 2007-2008.5 time span. This period corresponds to a La Niña event. While the 2011 La Niña is well explained by the mass plus steric components (see Boening et al., 2012, and Cazenave et al., 2014), it is surprising that the same data sets do not explain the negative GMSL anomaly related to the 2007-2008 La Niña. During the period February 2007 to June 2008, the correlation computed between the CCI, AVISO and CU residual curves and associated detrended GMSL amounts to $0.79,0.89$ and 0.92 , respectively. This high correlation and amplitude comparison suggests that the residual anomaly during this particular time span at least partly comes from the GMSL data. We cannot rule out however that the steric or ocean mass components also contribute. We will indeed see below that the observed discrepancy at this particular date also partly arises from errors in the GRACE and Argo data.

Over the whole time span (2005-2013), the correlations are $0.02,0.26$ and 0.55 for the CCI, AVISO and CU GMSL, respectively (see Table 2). The lowest correlation is obtained for the CCI data, indicating that the CCI residuals contain fewer GMSL short-term errors than the other two data sets. 


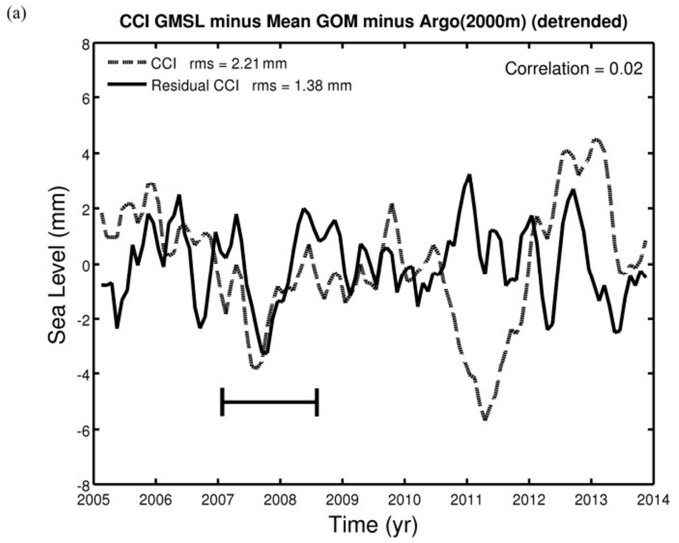

(b)

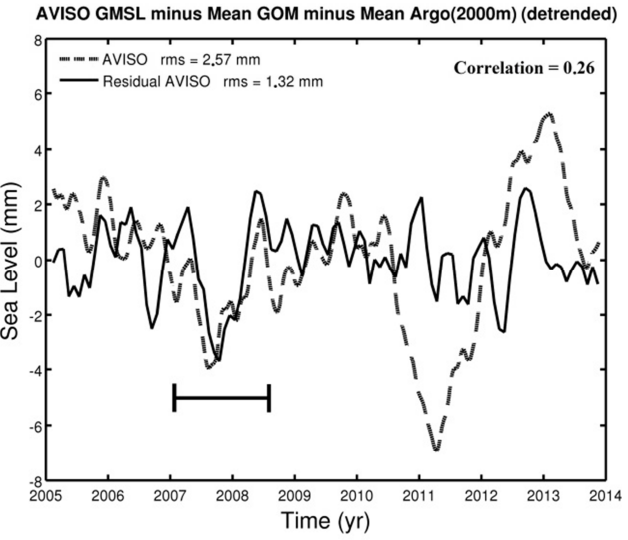

(c)

CU GMSL minus Mean GOM minus Mean Argo(2000m) (detrended)

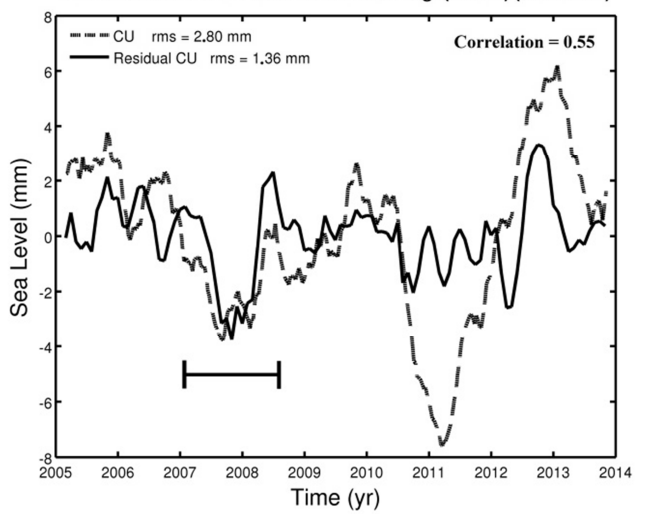

Figure 5. Detrended residual time series (January 2005-December 2013) (mean global ocean mass (GOM) and mean Argo-based steric sea level are used to compute the residual) for CCI (a), AVISO (b), and CU (c). The detrended GMSL from CCI, AVISO and CU are superimposed on each residual, respectively.

\subsection{Short-term (from sub-seasonal to interannual) errors in the global ocean mass}

We perform a similar comparison with the GRACE-based ocean mass products. For that purpose we only consider a single GMSL data set (i.e., CCI) and superimpose the detrended CCI residual time series computed separately for each ocean mass product with the corresponding detrended GRACE data set. These are shown in Fig. 6a-c. In Table 2 are given the correlation between the detrended residual curve and its associated detrended ocean mass component. The rms of the residual time series are also given.

The correlation is relatively high in all three cases, 0.46 , 0.55 and 0.57 for the CSR, GFZ and JPL data, respectively. The detrended global ocean mass and residual time series coincide almost perfectly between mid-2006 and mid-2007 and between mid-2009 and early 2012 (Fig. 6). This indicates that the short-term residual errors are largely affected by errors in GRACE-based ocean mass products. During the 2007-2008 La Niña, we also observe a significant correlation between the detrended ocean mass and associated residual of
0.57, 0.69 and 0.69, respectively, for the CSR, GFZ and JPL data.

\subsection{Short-term (from sub-seasonal to interannual) Argo-based steric sea level errors}

The rms of the residual time series based on the IPRC, JAMSTEC, SCRIPPS and KVS Argo data (linear trend removed from each time series) are in the range 1.3-1.6 $\mathrm{mm}$ (see Fig. 7 and Table 2). The lowest rms are obtained with SCRIPPS data when using the CCI and CU GMSL. For AVISO, the lowest rms are obtained with the KVS steric sea level. Overall, no best Argo product emerges, rms differences being small.

As mentioned previously, in the early part of the time series (2005-2006), we note larger dispersion between all Argo products compared to the subsequent years. These differences can be explained by a still incomplete global coverage of Argo data during this period (Lyman and Johnson, 2014; Roemmich et al., 2015). We note that the negative anomaly coinciding with the 2007-2008 La Niña is still present in the residual curves, with almost the same amplitude as in the 

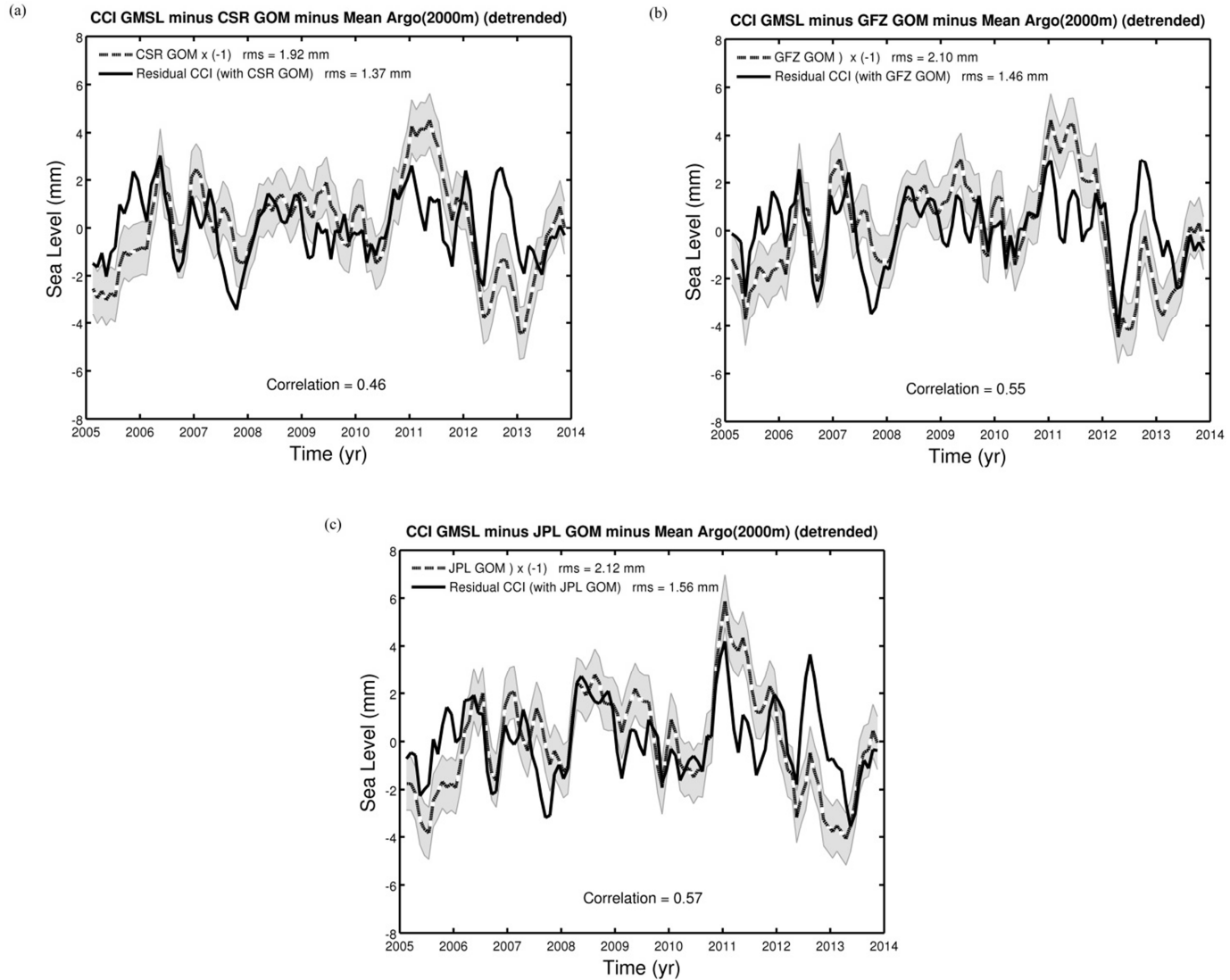

Figure 6. Detrended residual time series (January 2005-December 2013) computed with the CCI GMSL, mean Argo-based steric sea level and different ocean mass products. Associated detrended global ocean mass (GOM) time series superimposed. (a) CSR; (b) GFZ; (c) JPL.

GMSL data, indicating that the GMSL, or the mass or the Argo-based steric components (or all of them), are in error at that particular date.

We next examine the correlation between the residual time series and the detrended steric sea level, considering each Argo product successively. Figure 8a-d shows the detrended residual time series computed with the CCI GMSL superimposed on the detrended steric sea level time series. Each of the four steric products (SCRIPPS, IPRC, JAMSTEC and KVS) is considered. In each case the mean global ocean mass is used for computing the residual.

Examination of Fig. 8 shows that lowest residual rms are obtained with the SCRIPPS time series, but the rms difference with other Argo products is small. We also note that the short-term residual fluctuations are significantly correlated with the associated (detrended) Argo-based steric sea level time series at some periods, for example between mid-2010 and mid-2013, and especially when using the IPRC data. This indicates that the short-term fluctuations of the residuals partly reflect Argo-based steric sea level errors during this period.

\subsection{Sea level budget using the ORAS4 ocean reanalysis}

Errors in Argo-based steric sea level estimates arise from different sources (gaps in some regions, data editing, mapping techniques, etc.; Abraham et al., 2013; Lyman and Johnson, 2014; von Schuckmann et al., 2014). To investigate further the effect of Argo sampling, as well as other Argo data processing errors, on the residual time series, we recomputed the residuals using steric data from the ORAS4 ocean reanalysis (Balmaseda et al., 2013b). The integration is performed over the whole ocean depth range $(0-5350 \mathrm{~m})$ and between $66^{\circ} \mathrm{S}$ and $66^{\circ} \mathrm{N}$. Figure 9 shows the residual time series computed with the CCI GMSL and the mean of the four Argo products (black curve) and ORAS4 data (dotted curve). The detrended CCI GMSL is superimposed. Differences in residuals shown in Fig. 9 directly result from differences in the steric time series (all other parameters being the same). In terms of residual rms, we see little difference between the considered steric sea level products, even if at some periods (e.g., between mid-2010 and mid-2011) the steric curves do not agree very well with each other. For most of the time span, there is good coherence between the mean of the four Argo time series and ORAS4. However, the correlation be- 

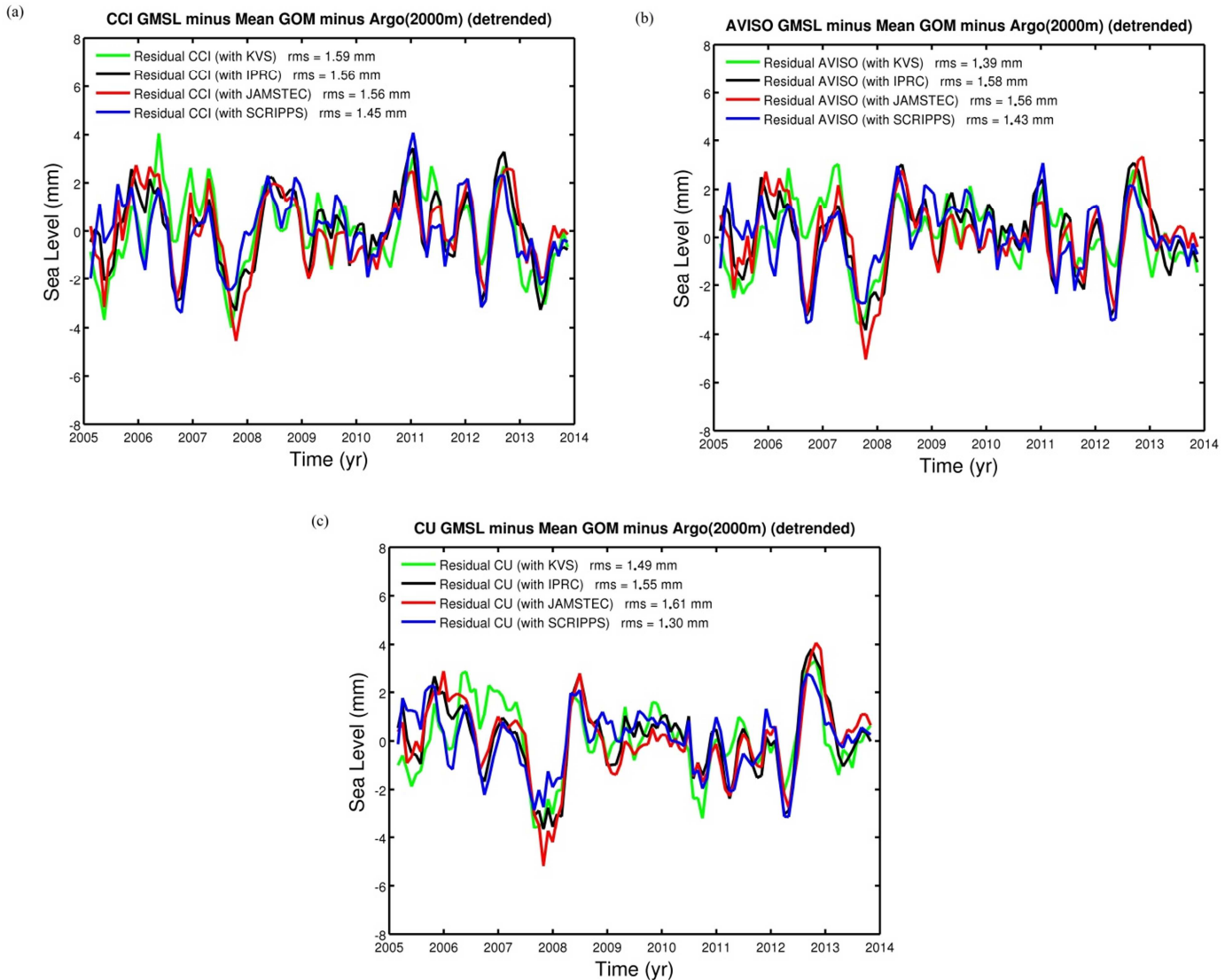

Figure 7. Residual time series (January 2005-December 2013) computed for each of the three GMSL: CCI (a), AVISO (b), and CU (c). Mean global ocean mass (GOM) and each of the four steric sea level products (IPRC, JAMSTEC, SCRIPPS and KVS) are used for computing the residuals.

tween the residuals and the detrended CCI GMSL is slightly lower when using the mean of the four Argo products than when using the reanalysis.

\section{Limitation of the approach presented in Sect. 5 (detrended analysis)}

One important objection that can be made to our approach is the following: suppose for example that only the GMSL and steric time series are in error (e.g., affected by white noise) and that the ocean mass data are perfect. Then, corresponding residuals and ocean mass time series would be correlated. Following the logic of our approach, one may thus conclude that it is the ocean mass that is in error. To investigate this potential drawback, we did the following test.

1. We first computed a "perfect" ocean mass time series from the difference between (observed) mean GMSL and mean Argo-based steric sea level.

2. Next, we applied a random noise to the mean GMSL and mean steric time series. Two cases have been considered: case 1 corresponds to a random error between -2 and $+2 \mathrm{~mm}$; case 2 corresponds to a random error between -4 and $+4 \mathrm{~mm}$ (corresponding to typical data uncertainties at interannual timescales). One-hundred drawings of lots have been performed for each case.

3. Then, we computed the corresponding residual time series (i.e., noisy GMSL minus noisy steric sea level minus perfect ocean mass), and correlated these with the "perfect" ocean mass time series.

Figure 10 shows a plot of these new correlations for the two cases. We note that most correlations fall below those of the nominal case (as described in Sect. 5.2). For case 1, in $82 \%$ of the simulations, the correlation worsens. For case 2 , this number increases to $92 \%$. We conclude that if the ocean mass time series is perfect and the GMSL and steric sea level data are noisy, the residuals appear poorly correlated with the ocean mass time series. Thus, a high correlation very likely reflects errors in the mass component.

In Sect. 5 (detrended residuals), we investigated temporally correlated errors between the three data sets (GMSL, steric sea level, ocean mass). This was the motivation for applying a correlation approach. The test described above 
(a)

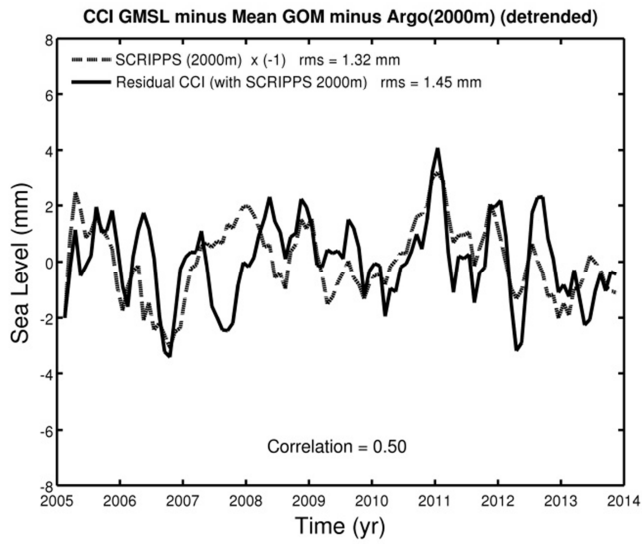

(c)

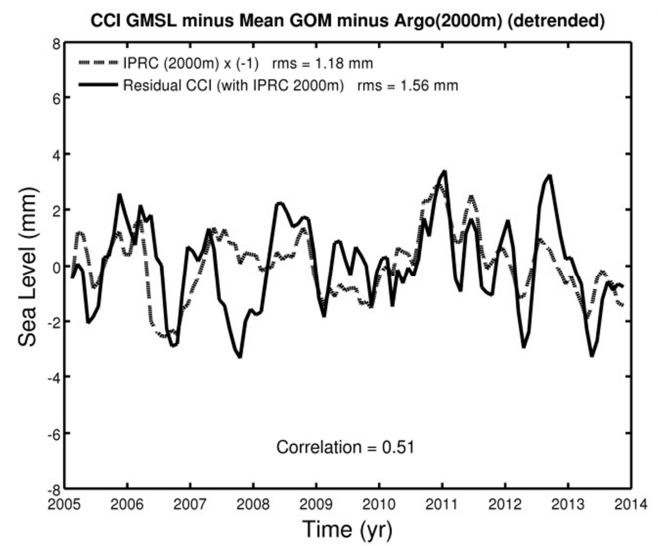

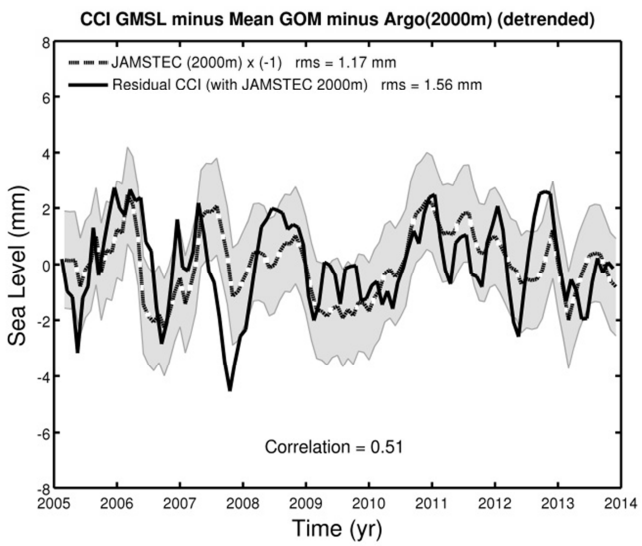

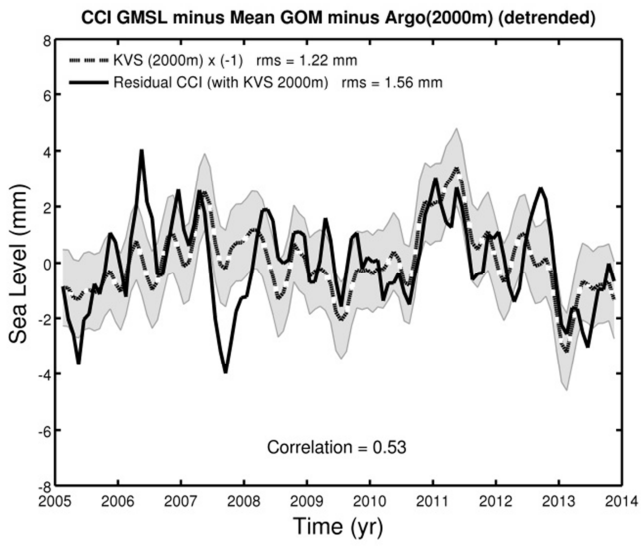

Figure 8. Detrended residual time series of CCI GMSL (January 2005-December 2013) computed with the mean global ocean mass (GOM) and each of the four steric sea level products: SCRIPPS (a), JAMSTEC (b), IPRC (c), and KVS (d); superimposed, the corresponding detrended steric sea level time series.

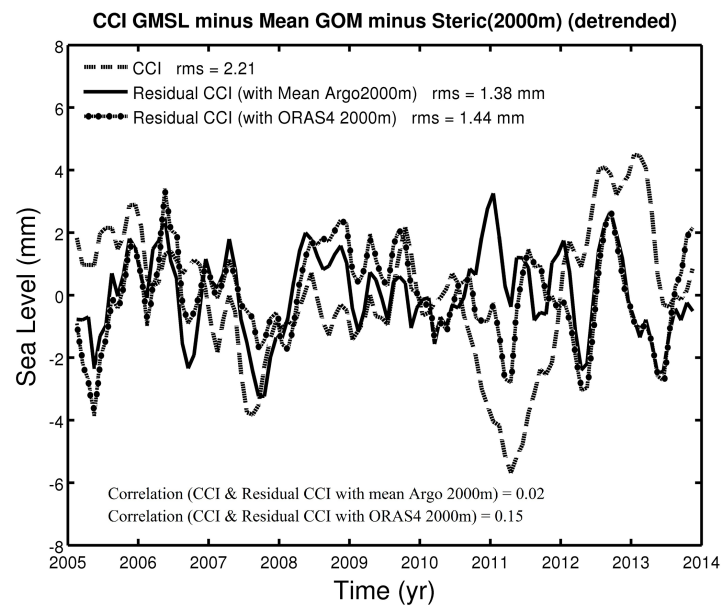

Figure 9. Residual time series (January 2005-December 2013) computed with the CCI GMSL, and the mean of the four Argo products (black curve) and ORAS4 data (dotted curve). The detrended CCI GMSL is superimposed (dashed curve).

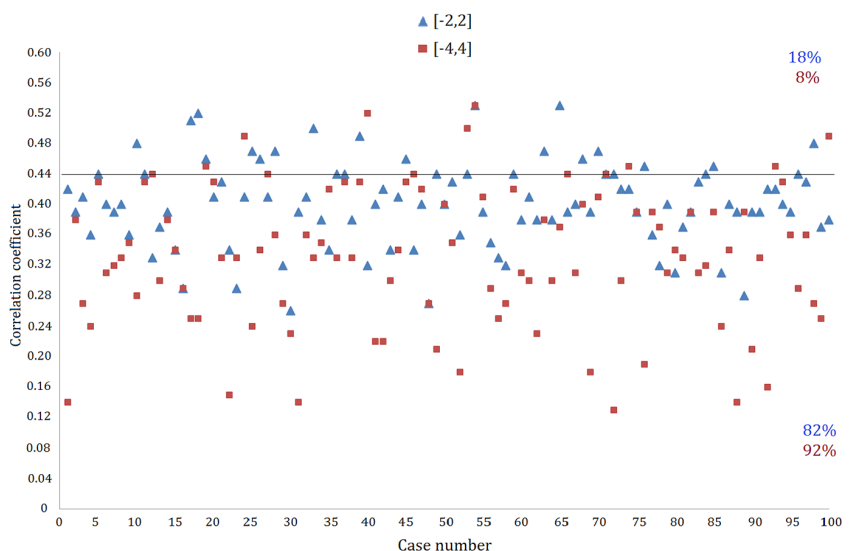

Figure 10. Correlation coefficient between residuals computed from noisy GMSL, noisy steric sea level and perfect ocean mass for 100 drawings of lots. Blue and red points correspond to cases 1 and 2, respectively (see text). The horizontal black line is the correlation of the nominal case (as described in Sect. 5.2). 


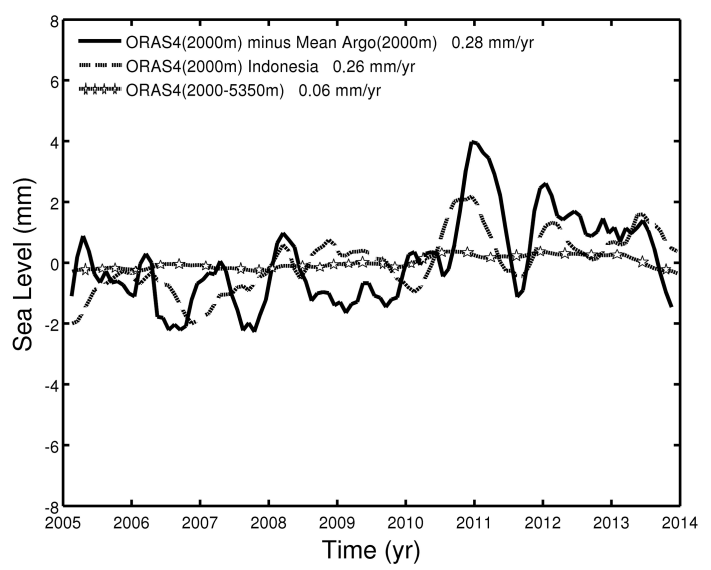

Figure 11. Steric sea level difference ORAS4 minus mean Argo time series (trend not removed) (black curve) (January 2005December 2013) up to $2000 \mathrm{~m}$ depth. The dashed curve is the Indonesian steric sea level time series estimated from ORAS4 up to $2000 \mathrm{~m}$ depth. The starry curve is the steric sea level time series from ORAS4 below $2000 \mathrm{~m}$ depth.

shows that the proposed method is meaningful and that the conclusions drawn in Sect. 5 are largely valid.

\section{Contribution of the Indonesian region and other areas not covered by Argo; uncertainty in the absolute residual trend}

The ORAS4 minus mean Argo time series (integration down to $2000 \mathrm{~m}$; trend not removed) is shown in Fig. 11. It displays significant short-term fluctuations, up to $4 \mathrm{~mm}$, and a trend of $0.28 \mathrm{~mm} \mathrm{yr}^{-1}$ (the ORAS4 steric trend being larger than the mean Argo trend). The ORAS4 reanalysis provides gridded steric data with no gaps, unlike the Argo products. In effect, the coverage of Argo data is not fully global, some regions (e.g., the Indonesian region and the Gulf of Mexico) not being covered. In Fig. 11, the ORAS4 contribution for the $2000-5350 \mathrm{~m}$ depth layer is also shown. It only explains the $0.06 \mathrm{~mm} \mathrm{yr}^{-1}$ sea level trend and (as expected) shows no short-term anomalies, as seen in the residual curve when using Argo. It is likely that both trend difference and shortterm anomalies seen in ORAS4 minus Argo time series result from gaps in the Argo geographical coverage (von Schuckmann et al., 2014). This is illustrated also in Fig. 11, which shows the steric sea level contribution from the Indonesian region (0-2000 m layer) computed with ORAS4. Part of the short-term anomalies of the difference curve is due to the lack of Argo data in this region (e.g., in 2011, coinciding with the La Niña event). Moreover, in terms of trend, the Indonesian region explains about the whole trend difference between Argo-based and ORAS4-based steric sea level. This suggests that the steric sea level trend estimated when using Argo is underestimated by $\sim 0.25 \mathrm{~mm} \mathrm{yr}^{-1}$. Hence, the residual (GMSL minus steric sea level minus ocean mass) trend may be in error (i.e., overestimated) by about this amount. This has important implications for the missing contributions derived from the sea level budget approach.

\section{Conclusion}

In this study, we estimated the sea level budget over the 2005-2013 time span using a large set of different observational products for the satellite altimetry-based sea level (six products), GRACE-based ocean mass (three products) and steric sea level (five data sets). We analyzed the residual time series (i.e., observed GMSL minus the sum of mass plus steric components) and attempted to attribute an error source to the residual trends and short-term residual anomalies. We found that errors in the GMSL products have a large impact on the residual trends. Trend differences of up to $0.55 \mathrm{~mm} \mathrm{yr}^{-1}$ between the different GMSL time series are reported. Such trend differences actually prevent one from accurately constraining missing contributions. These trend differences largely arise from differences in processing the Jason-1 satellite data (e.g., choice of the averaging method and geophysical corrections), as previously discussed by Masters et al. (2012) and Henry et al. (2014). While trying to identify the outliers and select the best corrections to be used is beyond the scope of the present study, we stress that this is definitely an important goal to pursue in the future.

In terms of absolute residual trends, we identified the contribution of the Indonesian region, not covered by Argo, as contributing about $0.25 \mathrm{~mm} \mathrm{yr}^{-1}$ (the computed residual trends being overestimated by about this amount). Contributions from other regional gaps in the Argo coverage (e.g., the Gulf of Mexico) estimated using ORAS4 data are found to be negligible as far as absolute residual trends are concerned. Thus, if we account for the residual trend overestimate due to lack of Argo data in the Indonesian region, the residuals computed with the CCI, AVISO and NOAA GMSL data (using Argo) become close to zero (i.e., $0.00 \mathrm{~mm} \mathrm{yr}^{-1}$, $0.04 \mathrm{~mm} \mathrm{yr}^{-1}$ and $0.16 \mathrm{~mm} \mathrm{yr}^{-1}$, respectively), while residual trends computed with the CU and GSFC data become negative $\left(-0.29 \mathrm{~mm} \mathrm{yr}^{-1}\right.$ and $-0.33 \mathrm{~mm} \mathrm{yr}^{-1}$, respectively).

This suggests that the sea level budget can be closed when using the CCI, AVISO and NOAA data. Hence, in these cases, the deep ocean (below $2000 \mathrm{~m}$ ) contribution appears negligible. It is worth mentioning that the residual trend (with the CCI GMSL) amounts to about zero (exactly $\left.0.00 \mathrm{~mm} \mathrm{yr}^{-1}\right)$ when using ORAS4 $(0-2000 \mathrm{~m}$; Indonesian region accounted for), in agreement with the above statements. Moreover, as mentioned above, the ORAS4 steric sea level trend for the $2000-5350 \mathrm{~m}$ depth range amounts to $0.06 \mathrm{~mm} \mathrm{yr}^{-1}$. However, further investigation is needed on that issue before drawing any definitive conclusion.

Another result from our study is the attribution of the short-term (from sub-seasonal to interannual) anomalies of the residual time series to errors in both Argo-based steric sea level and GRACE-based ocean mass. Short-term errors 
in these two components sometimes act in concert (thus amplifying the residual errors, e.g., during the 2007-2008 La Niña) or affect the residuals at different periods (e.g., over 2011-2014 for Argo, or in 2006 for GRACE).

To summarize the findings of this study, the main source of differences reported in the residual trends appears to be related to altimetry-based sea level data processing. In terms of absolute residual trends, missing Argo data in the Indonesian region contribute as much as $0.25 \mathrm{~mm} \mathrm{yr}^{-1}$. Accounting for this value leads to closure of the sea level budget, at least with the CCI, AVISO and NOAA GMSLs. At subseasonal to interannual timescales, the main source of uncertainty arises from short-term errors in GRACE and Argo data. More work is required by the different communities involved in either satellite altimetry or GRACE and Argo data processing, to clearly identify the causes of these errors and reduce/eliminate them. This is a challenge of primary importance if we want to precisely address a number of key issues, like the deep ocean heat uptake and its role in the current "hiatus".

Acknowledgements. We thank M. Balmaseda for providing us with the ORAS4 reanalysis data set. We also thank J. François Legeais and L. Zawadski for helpful discussions about errors in altimetry data processing. H. B. Dieng is supported by a $\mathrm{PhD}$ grant from the European Space Agency in the context of the Climate Change Initiative Programme.

Edited by: J. M. Huthnance

\section{References}

Ablain, M., Cazenave, A., Larnicol, G., Balmaseda, M., Cipollini, P., Faugère, Y., Fernandes, M. J., Henry, O., Johannessen, J. A., Knudsen, P., Andersen, O., Legeais, J., Meyssignac, B., Picot, N., Roca, M., Rudenko, S., Scharffenberg, M. G., Stammer, D., Timms, G., and Benveniste, J.: Improved sea level record over the satellite altimetry era (19932010) from the Climate Change Initiative project, Ocean Sci., 11, 67-82, doi:10.5194/os-11-67-2015, 2015.

Abraham, J. P., Baringer, M., Bindoff, N. L., Boyer, T., Cheng, L. J., Church, J. A., Conroy, J. L., Domingues, C. M., Fasullo, J. T., Gilson, J., Goni, G., Good, S. A., Gorman, J. M., Gouretski, V., Ishii, M., Johnson, G. C., Kizu, S., Lyman, J. M., Macdonald, A. M., Minkowycz, W. J., Moffitt, S. E., Palmer, M. D., Piola, A. R., Reseghetti, F., Schuckmann, K., Trenberth, K. E., Velicogna, I., and Willis, J. K.: A review of global ocean temperature observations: implications for ocean heat content estimates and climate change, Rev. Geophys., 51, 450-483, doi:10.1002/rog.20022, 2013.

Balmaseda, M. A., Trenberth, K., and Kallen, E.: Distinctive climate signals in reanalysis of global ocean heat content, Geophys. Res. Lett., 40, 1-6, doi:10.1002/grl.50382, 2013a.

Balmaseda, M. A., Mogensen, K., and Weaver, A. T.: Evaluation of the ECMWF ocean reanalysis system ORAS4, Q. J. Roy. Meteorol. Soc., 139, 1132-1161, doi:10.1002/qj.2063, 2013b.
Boening, C., Willis, J. K., Landerer, F. W., and Nerem, R. S.: The 2011 La Niña: so strong, the oceans fell, Geophys. Res. Lett., 39, L19602, doi:10.1029/2012GL053055, 2012.

Cazenave, A., Dieng, H., Meyssignac, B., von Schuckmann, K., Decharme, B., and Berthier, E.: The rate of sea level rise, Nature Climate Change, 4, 358-361, doi:10.1038/NCLIMATE2159, 2014.

Chambers, D. P. and Bonin, J. A.: Evaluation of Release-05 GRACE time-variable gravity coefficients over the ocean, Ocean Sci., 8, 859-868, doi:10.5194/os-8-859-2012, 2012.

Chambers, D. P. and Schroeter, J.: Measuring ocean mass variations from satellite gravimetry, J. Geodyn., 52, 333-343, 2011.

Chambers, D. P., Wahr, J., Tamisiea, M. E., and Nerem, R. S.: Ocean mass from GRACE and glacial isostatic adjustment, J. Geophys. Res., 115, B11415, doi:10.1029/2010JB007530, 2010.

Chen, X. and Tung, K.-K.: Varying planetary heat sink led to global warming slowdown and acceleration, Science, 345, 897-903, 2014.

Church, J. A., Clark, P. U., Cazenave, A., Gregory, J. M., Jevrejeva, S., Levermann, A., Merrifield, M. A., Milne, G. A., Nerem, R. S., Nunn, P. D., Payne, A. J., Pfeffer, W. T., Stammer, D., and Unnikrishnan, A. S.: Sea level change, in: Climate Change 2013: The Physical Science Basis. Contribution of Working Group I to the Fifth Assessment Report of the Intergovernmental Panel on Climate Change, edited by: Stocker, T. F., Qin, D., Plattner, G.-K., Tignor, M., Allen, S. K., Boschung, J., Nauels, A., Xia, Y., Bex, V., and Midgley, P. M., Cambridge University Press, Cambridge, UK and New York, NY, USA, 2013.

Dieng, H. B., Palanisamy, H., Cazenave, A., Meyssignac, B., and von Schuckmann, K.: The sea level budget since 2003: inference on the deep ocean heat content, Surv. Geophys., 36, 209-229, doi:10.1007/s10712-015-9314-6, 2015.

England, M. H., McGregor, S., Spence, P., Meehl, G. A., Timmermann, A., Cai, W., Gupta, A. S., McPhaden, M. J., Purich, A., and Santoso, A.: Recent intensification of wind-driven circulation in the pacific and the ongoing warming hiatus, Nature Climate Change, 4, 222-227, 2014.

Good, S. A., Martin, M. J., and Rayner, N. A.: EN4: quality controlled ocean temperature and salinity profiles and monthly objective analyses with uncertainty estimates, J. Geophys. Res.Oceans, 118, 6704-6716, doi:10.1002/2013JC009067, 2013.

Guemas, V., Doblas-Reyes, F. J., Andreu-Burillo, I., and Asif, M.: Retrospective prediction of the global warming slowdown in the past decade, Nature Climate Change, 3, 649-653, doi:10.1038/nclimate1863, 2013.

Hansen, J., Sato, M., Kharecha, P., and von Schuckmann, K.: Earth's energy imbalance and implications, Atmos. Chem. Phys., 11, 13421-13449, doi:10.5194/acp-11-13421-2011, 2011.

Held, I. M.: The cause of the pause, Nature, 501, 318-319, 2013.

Henry, O., Ablain, M., Meyssignac, B., Cazenave, A., Masters, D., Nerem, S., Leuliette, E., and Garric, G.: Investigating and reducing differences between the satellite altimetry-based global mean sea level time series provided by different processing groups, J. Geodesy, 88, 351-361, doi:10.1007/s00190-013-0687-3, 2014.

Johnson, G. C. and Chambers, D. P.: Ocean bottom pressure seasonal cycles and decadal trends from GRACE Release-05: Ocean circulation implications, J. Geophys. Res.-Oceans, 118, 42284240, doi:10.1002/jgrc.20307, 2013. 
Karl, T. R., Arguez, A., Huang, B., Lawrimore, J. H., McMahon, J. R., Menne, M. J., Peterson, T. C., Vose, R. S., and Zhang, H.: Possible artifacts of data biases in the recent global surface warming hiatus, Science, 348, 1469-1472, doi:10.1126/science.aaa5632, 2015.

Kosaka, Y. and Xie, S.-P.: Recent global warming hiatus tied to equatorial Pacific surface cooling, Nature, 501, 403-407, 2013.

Llovel, W., Willis, J. K., Landerer, F. W., and Fukumori, I.: Deepocean contribution to sea level and energy budget not detectable over the past decade, Nature Climate Change, 4, 1031-1035, doi:10.1038/NCLIMATE2387, 2014.

Loeb, N. G., Kato, S., Su, W. Y., Wong, T. M., Rose, F. G., Doelling, D. R., and Huang, X. L.: Advances in understanding top-of-atmosphere radiation variability from satellite observations, Surv. Geophys., 33, 359-385, doi:10.1007/s10712-0129175-1, 2012.

Lyman, J. M. and Johnson, G. C.: Estimating global ocean heat content changes in the upper $1800 \mathrm{~m}$ since 1950 and the influence of climatology choice, J. Climate, 27, 1945-1957, doi:10.1175/JCLIM-D-12-00752.1, 2014.

Masters, D., Nerem, R. S., Choe, C., Leuliette, E., Beckley, B., White, N., and Ablain, M.: Comparison of global mean sea level time series from TOPEX/Poseidon, Jason-1, and Jason-2, Mar. Geod., 35, 20-41, 2012.

Nieves V., Willis J. K., and Patzert W. C.: Recent hiatus caused by decadal shift in Indo-Pacific heating, Science, 1, 532-535, doi:10.1126/science.aaa4521, 2015.

Peltier, W. R.: Global glacial isostasy and the surface of the ice-age Earth: the ICE-5G (VM2) model and GRACE, Annu. Rev. Earth Pl. Sc., 32, 111-149, 2004.

Peters, G. P., Marland, G., Le Queré, C., Boden, T., Canadell, J. G., and Raupach, M. R.: Rapid growth in $\mathrm{CO}_{2}$ emissions after the 2008-2009 global financial crisis, Nature Climate Change, 2, 2 4, 2012.
Roemmich, D., Church, J., Gilson, J., Monselesan, D., Sutton, P., and Wijffels, S.: Unabated planetary warming and its ocean structure since 2006, Nature Climate Change, 5, 240-245, doi:10.1038/NCLIMATE2513, 2015.

Smith, D.: Has global warming stalled?, Nature Climate Change, 3, 618-619, doi:10.1038/nclimate1938, 2013.

Solomon, S., Rosenlof, K., Portmann, R., Daniel, J., Davis, S., Sanford, T., and Plattner, G.-K.: Contributions of stratospheric water vapour to decadal changes in the rate of global warming, Science, 327, 1219-1223, doi:10.1126/science.1182488, 2010.

Trenberth, K. E. and Fasullo, J. T.: Tracking Earth's energy, Science, 328, 316-317, 2010.

Trenberth, K. E. and Fasullo, J. T.: An apparent hiatus in global warming?, Earth's Future, 1, 19-32, doi:10.1002/2013EF000165, 2013.

Trenberth, K. E., Fasullo, J. T., and Balmaseda, M. A.: Earth's Energy imbalance, J. Climate, 27, 3129-3144, doi:10.1175/JCLID-13-00294.1, 2014.

von Schuckmann, K. and Le Traon, P.-Y.: How well can we derive Global Ocean Indicators from Argo data?, Ocean Sci., 7, 783791, doi:10.5194/os-7-783-2011, 2011.

von Schuckmann, K., Sallée, J.-B., Chambers, D., Le Traon, P.-Y., Cabanes, C., Gaillard, F., Speich, S., and Hamon, M.: Consistency of the current global ocean observing systems from an Argo perspective, Ocean Sci., 10, 547-557, doi:10.5194/os-10547-2014, 2014.

Watanabe, M., Kamae, Y., Yoshimori, M., Oka, A., Sato, M., Ishii, M., Mochizuki, T., and Kimoto, M.: Strengthening of ocean heat uptake efficiency associated with the recent climate hiatus, Geophys. Res. Lett., 40, 3175-3179, doi:10.1002/grl.50541, 2013. 